\title{
Enhancement of tribological and thermo-mechanical properties of phenolic resin friction composites by improving interactions between elastomeric phase and matrix resin
}

\author{
Prosenjit Ghosh $^{1} \cdot$ Kinsuk Naskar $^{1} \cdot$ Narayan Chandra Das $^{1}$ (D)
}

Received: 14 June 2020 / Accepted: 15 October 2020 / Published online: 28 October 2020

(c) Springer Nature Switzerland AG 2020

\begin{abstract}
New elastomer-modified brake friction composites with the identical composition, but differing in the type of rubber, were developed by altering polar/non-polar elastomeric phases into the phenolic resin matrix. Effect of dispersion and interaction of the polar/non-polar rubbers with the matrix resin on dry sliding wear characteristics of the friction composites was investigated using a laboratory-scale pin-on-disc tribometer. The composites were prepared by hot mixing followed by compression molding and post-curing at a high temperature. Coefficient of friction (COF) and specific wear rate of the composites sliding against a cast-iron disc were measured and analyzed. Polar acrylonitrile-butadiene rubber (NBR, both powder, and bale rubber), and non-polar styrene-butadiene rubber (SBR) and ethylene-propylene-diene monomer (EPDM) were used with the phenolic resin where rubber islands and its polarity played the key role in delayed stress dissipation, while the hard matrix phase contributed to the intrinsic strength of the composites. This work describes how the distribution and interaction of polar and non-polar rubbers with the matrix resin influence the performance of brake friction composites. NBR (powder)-phenolic composite showed the highest stable average COF of 0.52 as compared to 0.36 for EPDM-based composite. NBR (powder)-based composite also exhibited $\sim 1.5$ times better specific wear rate $\left(4.9 \times 10^{-3} \mathrm{~mm}^{3} \mathrm{~N}^{-1} \mathrm{~m}^{-1}\right)$ than EPDM-based composite $\left(7.2 \times 10^{-3} \mathrm{~mm}^{3} \mathrm{~N}^{-1} \mathrm{~m}^{-1}\right)$. However, EPDM rubber-based composite showed a significant enhancement in thermal conductivity $(0.43 \mathrm{~W} / \mathrm{m} \mathrm{K})$. Morphological analyses revealed that the dispersion of rubber phase in phenolic matrix played a significant role in transforming the wear mechanism from abrasive to adhesive.
\end{abstract}

Keywords Elastomeric phase $\cdot$ Friction composite $\cdot$ Wear $\cdot$ Thermal conductivity

\section{Introduction}

Fiber-reinforced organic composites find wide applications as brake friction materials to control the acceleration/deceleration in a range of vehicles, including light motor vehicle to heavy-duty trucks to railroad wagon and coaches [1]. The tailor-ability of properties of such composites is useful in enhancing performance of the friction composites. However, developing a new friction composite with advanced properties is always a challenging task because that requires fine-tuning of different performance properties such as mechanical, frictional, and thermal [2]. In addition, the friction material must exhibit a high and stable coefficient of friction (COF) with low

Electronic supplementary material The online version of this article (https://doi.org/10.1007/s42452-020-03728-5) contains supplementary material, which is available to authorised users.

Narayan Chandra Das, ncdas@rtc.iitkgp.ac.in | ${ }^{1}$ Rubber Technology Centre, Indian Institute of Technology, Kharagpur, West Bengal 721302, India. 
wear loss both from its surface and counter surface [3]. To satisfy all these complex requirements, friction material is made of ten or more different components, and the formulation is often developed through a series of trial-anderror process at the brake industries because the performance of the friction material also depends on operating variables like load, speed, temperature along with the type and amount of raw materials [4]. Therefore, raw material selection is an important step in developing a new brake friction compound for advanced applications. Prior knowledge of properties of raw materials makes it easy to select the right ingredients [5].

In general, four types of raw materials e.g. polymer matrix, fibrous reinforcement, friction modifiers, and fillers are used in multi-phase organic friction composites [6]. The mutual interactions of the raw ingredients both in a positive and negative way influence the overall performance of the composite. The polymer matrix acts as a binder and maintains the overall integrity of the system. The binder matrix also influences wear resistance, friction coefficient, and thermal resistance of the friction composite. In addition, the polymer matrix controls noise propensity during brake application. Importantly, the process parameters to fabricate the friction material largely depend on the binder resin [7]. Straight or modified phenol formaldehyde (PF) resins are used as the polymer matrix for a long time because of advantages like good processability, acceptable thermal stability, and moderate mechanical strength [8]. However, the inherent structural rigidity of $\mathrm{PF}$ resin originated from its rigid aromatic structure is a serious concern that needs to overcome to improve the mechanical flexibility and damping properties of PF resin-based brake friction materials. Rubbery impact modifiers like styrene-butadiene rubber (SBR), nitrile-butadiene rubber (NBR), ethylene propylene diene monomer (EPDM) rubber, etc. can act as important friction modifiers to PF resin-based friction composite. Rubber improves mechanical flexibility and damping properties of friction composite owing to unique viscoelastic properties [9]. Rubber enhances the compressibility of the friction material and makes conformable to the counter surface, thus helps to reduce thermal damage of the friction couple.

Both virgin and reclaimed rubbers are used to reduce structural rigidity of PF resin. Rubber possesses high flexibility because of low glass transition temperature. According to Arjmand and Shojaei [10], the viscoelastic behavior of rubber plays an important role in controlling different frictional attributes of friction composites. Rubbers exhibit wide viscoelastic responses over a particular range of temperatures depending on their chemical structure and thermal stabilities. Therefore, the selection of rubber is an important task in making elastomer-modified high-performance PF resin friction composite. Literature suggests that very limited works have been carried out, emphasizing the impact of rubber on friction material's formulation. Saffer and Shojaei [11] varied the ratio of PF resin to SBR to investigate the effect of volume fraction of rubber on physical, mechanical, and tribological properties of PF resin-based friction composite. They found that a higher volume fraction of SBR could improve fade and recovery characteristics of the composite at a higher sliding velocity. Nidhi et al. [12] studied the effect of modification of straight PF resin by NBR on fade and recovery behavior of a non-asbestos organic (NAO) composite. They concluded that NBR modification of PF resin is beneficial in improving recovery behavior of the composite, but at the expense of fade resistance. Saffer et al. [13] in another work proposed a semi-empirical model to correlate COF with friction interface temperature for rubber-based friction material. They showed that the rubber to glass transition temperature of rubber has a significant influence on fade and wear behavior of the composite. According to Liu et al. [14], nano-powdered rubbers (SBR and NBR) could be more effective for manufacturing friction materials compared to conventional rubbers. The COF of the prepared composites varied steadily with temperature and the wear rate also decreased using nano powdered rubbers. Chang et al. [15] investigated the effect of rubber particle size on the friction and wear characteristics of brake friction materials. For that purpose, they prepared friction materials with two different sizes of recycled rubbers (particle size $\sim 75$ and $450 \mu \mathrm{m}$ ) and concluded that small rubber particles can increase the level of friction and frictional stability, but also increase the wear rate. However, there is no report available in the open literature regarding the influence of polar-polar and polar-non polar interaction between the elastomeric phase and PF matrix on tribological, mechanical, and thermal properties of PF resin-based friction composite. PF resin is a polar polymer; therefore, systematic alteration of the polar/non-polar elastomeric phases in the polar polymer matrix can influence tribological, mechanical, and thermal characteristics of the composites. The combination of hard resin matrix and soft viscoelastic rubber phases could be interesting to mitigate the premature wearing that has a direct impact on the longevity and tribological performances of brake friction material. The objective of the present work is to explore the effect of distribution and interaction of polar and nonpolar rubbers with the matrix resin on the performance of a PF resin-based friction composite for advanced applications. Extensive experimental work has been carried out to compare the influence of rubber-resin interaction on the dry sliding wear characteristics of the friction composites. For this purpose, polar NBR (both powder and bale rubber) and non-polar SBR and EPDM are selected. The effect of these polar and non-polar rubbers on the various aspects 
of frictional, thermal, and mechanical properties of the elastomer-modified PF resin composite is systematically investigated. A qualitative dependence of frictional properties on the mechanical strength and thermal stability of the composite has also been depicted. The surface morphological behavior of the composites is correlated with the wear mechanism.

\section{Experimental details}

\subsection{Materials and sample preparation}

PF resin-based (novolac type, obtained from a local source) four compounds were prepared in which the rubber was kept as the variable. For this purpose, four rubbers e.g. powdered acrylonitrile-butadiene rubber (NBR powder), and three conventional bale rubbers like NBR, styrenebutadiene rubber (SBR), and ethylene-propylene-diene monomer (EPDM) were used to prepare the compounds. The prepared compounds were designated as $\mathrm{N}(\mathrm{P}), \mathrm{N}, \mathrm{S}$, and $E$, respectively; where $N$ stands for NBR, $S$ stands for SBR, E stands for EPDM, and P stands for powdered rubber. The relative proportion of rubber was kept $70 \mathrm{phr}$ (parts per hundred resin) in all formulations. The prepared friction composites consisted of several ingredients viz. aramid pulp (HP Heracron 100, the Netherlands) and lapinus fiber (RBC 100 from Lapinus intelligent fibers, the Netherlands) were used as fibrous reinforcements, calcined petroleum coke (CPC, from India Carbon Ltd.) was taken as a friction modifier, synthetic graphite powder (from Loba Chemicals) was used as a solid lubricant, aluminum chips (from Kanagavalli Metal Industries, Chennai, India) was added as the metallic filler, and barites (Rankem) was taken as a space filler in designing the formulations. The composites also contained rubber additives like zinc oxide, stearic acid; 1,2 dihydro 2,2,4-trimethyl quinoline (TQ), semi-reinforcing furnace (SRF) carbon black, sulphur, and $\mathrm{N}$-cyclohexyl-2-benzothiazole sulfonamide (CBS) to cure the rubber phase, whereas hexamethylenetetramine (Hexamine, from Merck Chemicals, India) was used to cure PF resin. The relative amounts of all ingredients were kept constant with respect to $100 \mathrm{phr}$ of PF resin in all composites. The detailed formulations are shown in Table 1.

The mixing of all raw ingredients was carried out in a Brabender Plasticorder (model PLE-330, with cam-type rotor and $60 \mathrm{~cm}^{3}$ capacity) at $120^{\circ} \mathrm{C}$ and $60 \mathrm{rpm}$ rotor speed for $10 \mathrm{~min}$. The mixing was completed in three stages to reduce the chances of fiber agglomeration and macroscopic inhomogeneity of the major ingredients like fibrous reinforcements and fillers in PF resin matrix. At first, rubber and rubber additives were mixed homogeneously for $4 \mathrm{~min}$ to ensure proper dispersion of the additives in the rubber phase. Then gradually fibers (aramid pulp/lapinus fiber), graphite, CPC, aluminum chips, and barites were added and mixed for 3 more minutes. PF resin and hexamine were added in the final stage of mixing and mixed for another $3 \mathrm{~min}$. Thus, the total mixing cycle was kept for 10 min to ensure even distribution of the ingredients in the composites (Supplementary Fig. S1 for more details). The mixed compound was then pulverized and cooled to room temperature. The compounds were molded in a hydraulic press at $170{ }^{\circ} \mathrm{C}$ for $15 \mathrm{~min}$ under a hydraulic pressure of $10 \mathrm{MPa}$. From each batch, a thin sheet $(100 \mathrm{~mm} \times 100 \mathrm{~mm} \times 2 \mathrm{~mm})$, a square block (40 $\mathrm{mm} \times 40 \mathrm{~mm} \times 10 \mathrm{~mm}$ ), and a rectangular bar $(120 \mathrm{~mm} \times 15 \mathrm{~mm} \times 10 \mathrm{~mm}$ ) were prepared by compression molding. The molded samples were post cured at $200{ }^{\circ} \mathrm{C}$ for $8 \mathrm{~h}$ to ensure proper curing of PF resin. The details of processing conditions are summarized in Table 2 .

Table 1 Compound formulations

\begin{tabular}{|c|c|c|c|c|c|c|c|}
\hline \multicolumn{8}{|l|}{ Compositions } \\
\hline \multicolumn{2}{|l|}{$\mathrm{N}(\mathrm{P})$} & \multicolumn{2}{|l|}{$\mathrm{N}$} & \multicolumn{2}{|l|}{$\mathrm{S}$} & \multicolumn{2}{|l|}{$E$} \\
\hline Ingredients & $\mathrm{phr}$ & Ingredients & phr & Ingredients & phr & Ingredients & phr \\
\hline PF resin & 100 & PF resin & 100 & PF resin & 100 & PF resin & 100 \\
\hline Hexamine & 10 & Hexamine & 10 & Hexamine & 10 & Hexamine & 10 \\
\hline NBR (powder) & 70 & NBR (bale form) & 70 & SBR & 70 & EPDM & 70 \\
\hline $\mathrm{ZnO}+$ St. Acid $+\mathrm{S}+\mathrm{CBS}+\mathrm{TQ}$ & 9 & $\mathrm{ZnO}+$ St. Acid $+\mathrm{S}+\mathrm{CBS}+\mathrm{TQ}$ & 9 & $\mathrm{ZnO}+$ St. Acid $+\mathrm{S}+\mathrm{CBS}+\mathrm{TQ}$ & 9 & $\mathrm{ZnO}+\mathrm{St} . \mathrm{Acid}+\mathrm{S}+\mathrm{CBS}+\mathrm{TQ}$ & 9 \\
\hline SRF black & 40 & SRF black & 40 & SRF black & 40 & SRF black & 40 \\
\hline Aramid pulp & 30 & Aramid pulp & 30 & Aramid pulp & 30 & Aramid pulp & 30 \\
\hline Lapinus fiber & 300 & Lapinus fiber & 300 & Lapinus fiber & 300 & Lapinus fiber & 300 \\
\hline Graphite & 30 & Graphite & 30 & Graphite & 30 & Graphite & 30 \\
\hline CPC & 200 & CPC & 200 & CPC & 200 & $\mathrm{CPC}$ & 200 \\
\hline Aluminum chips & 75 & Aluminum chips & 75 & Aluminum chips & 75 & Aluminum chips & 75 \\
\hline Barites & 200 & Barites & 200 & Barites & 200 & Barites & 200 \\
\hline
\end{tabular}


Table 2 Processing details of fabrication

\begin{tabular}{ll}
\hline Procedure & Conditions \\
\hline Internal mixing: & Mixing temperature-120 ${ }^{\circ} \mathrm{C}$ \\
Brabender Plasticorder & Duration of mixing $-10 \mathrm{~min}$ \\
& Rotor speed-60 rpm \\
Compression molding & Molding temperature-170 ${ }^{\circ} \mathrm{C}$ \\
& Molding time-15 min \\
& Compression pressure-10 MPa \\
Post curing & At $200{ }^{\circ} \mathrm{C}$ for $8 \mathrm{~h}$ \\
\hline
\end{tabular}

\subsection{Physico-mechanical characterization}

Several physico-mechanical tests were carried out to understand the influence of dispersion of rubber phase in PF matrix of the composites. Density of the composite (molded square block sample, three samples) was measured by applying the standard water displacement technique according to ASTM D 792. Hardness of the same square block sample was measured in Rockwell $R$ scale following ASTM D 785 standard using a Rockwell hardness tester. Hardness was taken as the average of five readings from five different spots of the composite. The block sample was then drilled to produce a powder to measure ash percentage and determine acetone extractable mass. Ash content was measured by roasting the powder in a muffle furnace at $700{ }^{\circ} \mathrm{C}$ for $4 \mathrm{~h}$. Acetone extraction was carried out in a Soxhlet apparatus for $24 \mathrm{~h}$. Ash content and acetone extraction results were the averages of three measurements with $\pm 5 \%$ standard deviation. Compressive strength and flexure strength of the composite were measured in an Instron universal testing machine (UTM). The square block composite sample was used to measure compressive strength following ASTM D 695 method. On the other hand, the rectangular bar sample was used to measure flexure strength using the standard three-point bending procedure. At least five samples were tested from each batch to check the compressive strength and flexure strength of the composites.

\subsection{Friction and wear characteristics}

COFs and wear (volume) of the friction composites were measured in a pin-on-disc tribometer (Phoenix TE97 friction and wear demonstrator, single-phase ac $50 / 60 \mathrm{~Hz}$ ) following ASTM G99-17 standard. Details of instrumentation of the tribometer were given in our recent publication [16]. The tribometer is bench mounted and horizontal loading assisted pin-on-disc instrument. The device instrumentation allows computerized data acquisition and has a motor and a reduction gearbox with a reduction ratio of 20:1. The gearbox carries the test disc spindle. Working load is applied manually through screw acting on an extension spring. A slotted opto switch and 60 tooth wheels measure the speed of the rotating disc. A force transducer allows the measurement of friction and the load, while a displacement transducer measures the wear of the friction materials. Electrical contact potential during the test is recorded by the Lun-Furry circuit and an electrical slip ring coupled with electrical insulation of the specimen carrier. A constant rpm-mode testing condition was used to emphasize the importance of elastomer-matrix interaction on the wear process and the operative wear mechanism. Compression-molded die-cut circular specimen having $2 \mathrm{~mm}$ thickness and $12.5 \mathrm{~mm}$ diameter was used as the pin against the counter disc. The pin sample was attached to the sample holder using an adhesive. A cast-iron disc (Brinell hardness range HB 180-220) of $50 \mathrm{~mm}$ diameter was used as the counter face. The average surface roughness of the disc was in the range of 0.8-1.0 $\mu \mathrm{m}$ (measured by the Optical image analyzer, Leica DMLM). The experiment was done at a sliding speed of $150 \mathrm{rpm}$ under a constant load of $50 \mathrm{~N}$ for $30 \mathrm{~min}$. The tests were done under the same environmental conditions, e.g. room temperature and humidity. At least five measurements were carried out from the same batch, and standard deviations of COF and volume wear were obtained in the range of $\pm 5 \%$.

\subsection{Thermogravimetric analysis (TGA)}

Thermal stability of the composites was determined by TGA using a METTLER-TOLEDO AG apparatus (The Netherland, model no. ME-51709822G) following ASTM E1131-20 standard. $10 \mathrm{mg}$ sample was programmed to be heated from 50 to $800^{\circ} \mathrm{C}$ at a heating rate of $20^{\circ} \mathrm{C} / \mathrm{min}$ under a nitrogen atmosphere. $T_{\max }$ (maximum degradation temperature) and $\mathrm{T}_{0}$ (onset of degradation) were measured and analyzed for each sample.

\subsection{Thermal conductivity}

Thermal conductivity measurements of the composite specimen (dimension: $100 \mathrm{~mm} \times 100 \mathrm{~mm} \times 2 \mathrm{~mm}$ ) were carried out under steady-state heat flux conditions using a guarded hot plate apparatus over the temperature range of $30-200^{\circ} \mathrm{C}$ following ASTM C 177 method.

\section{Results and discussion}

\subsection{Physico-mechanical properties}

The influence of rubber on different physico-mechanical properties of the composites is evaluated for comparative assessment. Table 3 shows the results of density, hardness, 
Table 3 Physical, chemical and mechanical properties of the composites

\begin{tabular}{llllllll}
\hline Sample & Density $(\mathrm{g} / \mathrm{cc})$ & & Hardness (Rockwell R) & Ash content (\%) & $\begin{array}{l}\text { Acetone } \\
\text { extraction (\%) }\end{array}$ & $\begin{array}{l}\text { Compressive } \\
\text { strength (MPa) }\end{array}$ & $\begin{array}{l}\text { Flexure } \\
\text { strength } \\
(\mathrm{MPa})\end{array}$ \\
\cline { 2 - 6 } & Before cure & After cure & & & & & \\
\hline $\mathrm{N}(\mathrm{P})$ & 2.13 & 2.04 & $77.8 \pm 3.9$ & $56.66 \pm 2.83$ & $2.50 \pm 0.13$ & $111.0 \pm 5.6$ & $250 \pm 13$ \\
$\mathrm{~N}$ & 2.16 & 2.04 & $83.9 \pm 4.2$ & $57.10 \pm 2.85$ & $1.69 \pm 0.08$ & $99.8 \pm 5.0$ & $441 \pm 21$ \\
$\mathrm{~S}$ & 2.11 & 2.04 & $96.3 \pm 4.8$ & $56.06 \pm 2.80$ & $2.32 \pm 0.12$ & $90.6 \pm 4.5$ & $178 \pm 09$ \\
$\mathrm{E}$ & 2.07 & 2.02 & $111.5 \pm 5.6$ & $56.93 \pm 2.82$ & $4.77 \pm 0.24$ & $51.9 \pm 2.6$ & $122 \pm 06$ \\
\hline
\end{tabular}

ash content, acetone extraction, compressive strength, and flexure strength of the composites. Densities of NBR and SBR based composites are almost the same since NBR and SBR have almost identical densities i.e. $\sim 1.0 \mathrm{~g} / \mathrm{cm}^{3}$. However, density of EPDM-based composite is lesser compared to NBR and SBR based composites, which is likely because of the lower density of EPDM $\left(0.85 \mathrm{~g} / \mathrm{cm}^{3}\right)$ than NBR and/or SBR. As expected, density of all composites decreases after oven curing due to evolution of volatile organic matters during the oven curing process. Composite E shows higher hardness than the others. However, both compressive and flexure strengths of composite $E$ are lower than NBR and SBR based composites. This suggests that higher the surface hardness of the composite lower is the compressive strength. Table 3 shows that the ash percentage of all composites is almost equal, which could be because the rubbers possess almost similar thermal stability as evident from TGA (discussed later). The acetone extraction gives the amount of uncured resin in the composites. NBR based composites, $N(P)$ and $N$ yield the least acetone extract while EPDM based composite $\mathrm{E}$ gives the highest acetone extracted value. Therefore, a correlation could be made between acetone extract and flexure strength that, lower the acetone extractable mass, higher is the flexure strength. A lower acetone extract indicates a better three-dimensional network structure formation in PF resin composite system.

\subsection{Friction and wear characteristics}

Figure 1 shows COF versus sliding time plot of the prepared composites under an applied load of $50 \mathrm{~N}$. It is obvious that the trend and extent of variation of COF with sliding time depend on the rubber component present in the system. COF of composite $N(P)$ increases continuously with sliding time. $N(P)$ also exhibits minimum frictional undulations (waviness in the graph) during the friction test, which suggests an excellent conformability with the cast-iron counter disc. On the other hand, composite $\mathrm{N}$ (the other NBR based composite) shows considerable frictional undulations during the friction test. In the case of composites $S$ and $E$, COF remains almost constant and

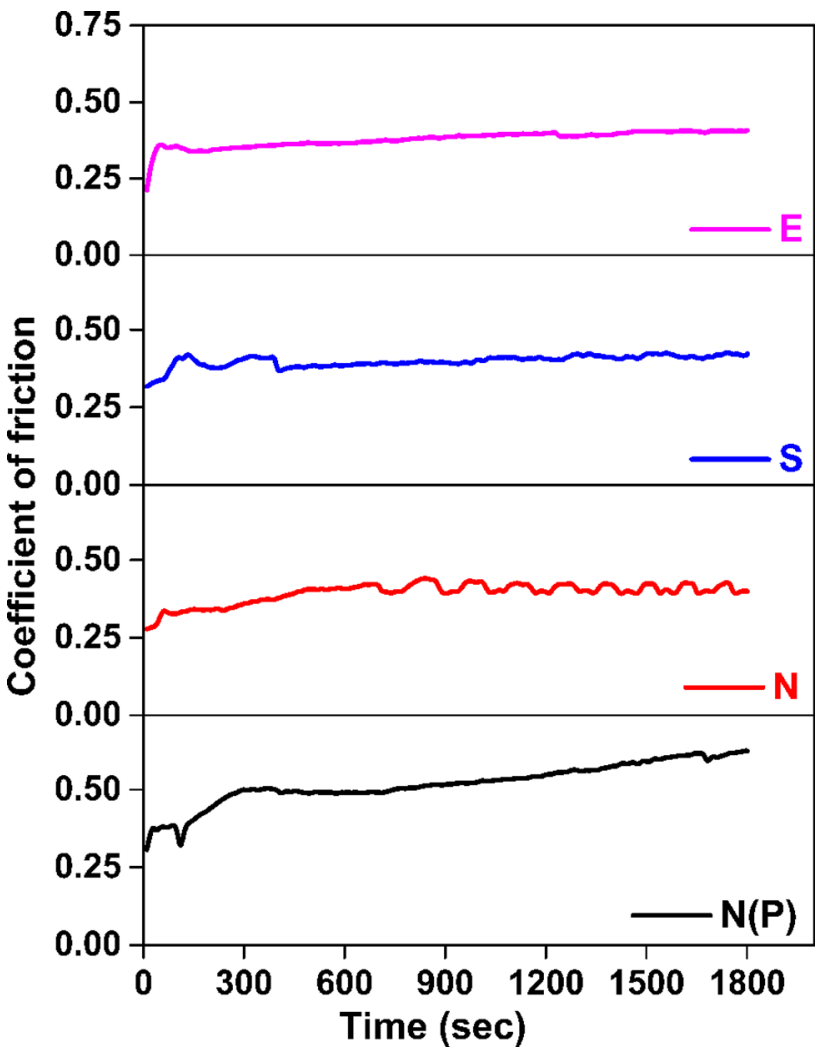

Fig. 1 COF versus sliding time plot of the composites

changes very little with sliding time. According to Fig. 2a, composite $N(P)$ exhibits the highest average COF, but the other composites i.e. N, E, and S show almost similar average COF. Figure $2 \mathrm{c}$ reveals that frictional fluctuation in terms of $\mathrm{COF}_{\max }-\mathrm{COF}_{\min }$ is the highest in $\mathrm{E}$ and the least in $\mathrm{S}$, while $\mathrm{N}(\mathrm{P})$ and $\mathrm{N}$ exhibits intermediate values. In the present investigation, since rubber was kept as the only variable, so the differences in the magnitude of different COFs could be ascribed to the change in rubber type. In addition, the better dispersion of NBR powder in $\mathrm{PF}$ matrix could be attributed to the highest average COF for composite $N(P)$ because the dispersion of a component in a multi-phase friction composite influences the relative amount of contact during sliding as reported by 


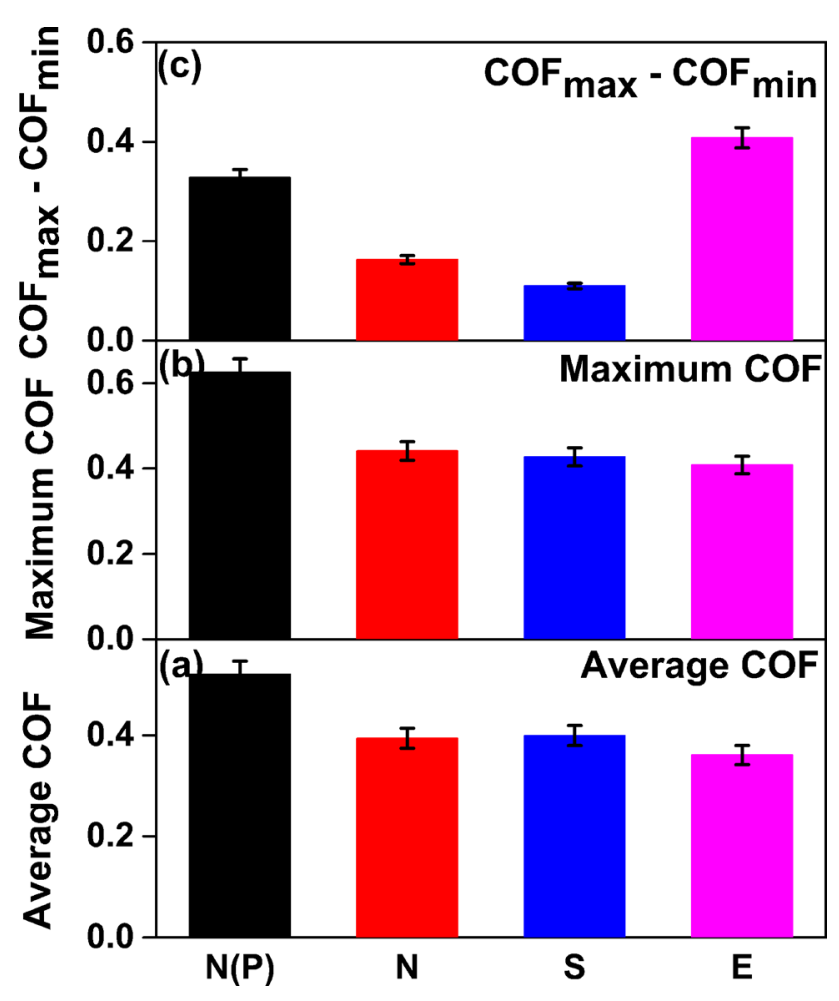

Fig. 2 Different COFs of the composites: (a) average COF, (b) maximum COF, (c) difference between the maximum and minimum COFs

Gweon et al. [17]. As predicted from Fig. 1, the friction force for composite $N(P)$ increases gradually with sliding time indicating typical positive friction-sliding time relationship. The higher friction force for composite $N(P)$ suggests that the surface properties like adhesion [18] and tangential stiffness [19] of $\mathrm{N}(\mathrm{P})$ are different compared to the other rubber-based composites. Both $N(P)$ and $N$ are NBR based composites; hence it is reasonable to assume that the shear strength of the contact surface is identical for these two composites. Therefore, the higher average COF of $N(P)$ suggests that the contact area on the sliding surface is larger in $N(P)$ than $N$ because the shear force is proportional to the deformed area produced by the shear action during sliding [14].

In general, three competitive friction mechanisms e.g. adhesive, deformation, and plowing operate at the friction interface during sliding. Adhesive friction acts at the real contact areas of friction pair (known as the adhesive zone) and works against the sliding of friction couple by developing interfacial shear stresses at the interface. Deformation is the prevailing friction mechanism in the cohesive region (beneath the adhesive zone) of the friction couple. Plowing occurs due to the mechanical interlocking of surface asperities or by the penetration of hard worn-out particles into the softer material (i.e. the friction material). Therefore, the mechanical properties of friction composite like strength, stiffness, and compressibility play a crucial role to resist the deformation and plowing action during sliding [20]. According to Bowden and Tabor [21], adhesive friction is the manifestation of interfacial energy and interfacial shear strength of the friction pair. Interfacial shear stress at the friction interface affects mechanical deformation of the friction composite in the cohesive region during the friction test. Intermolecular forces of the friction pair control developing interfacial shear stress at the friction interface, thereby control the adhesive component of friction which resists the sliding of the friction couple against each other. Intermolecular force is a material property of a composite system, thus the interaction of the rubber component with PF matrix at the molecular level becomes important in controlling the intermolecular force and the resulting interfacial stress. Rubber acts as a source of a shock absorber at the friction interface. NBR and SBR possess higher surface energy than the EPDM rubber. Hence, NBR and SBR based formulations incur much more interactions with PF matrix which could cause higher interfacial stress and subsequent lower frictional fluctuations for composite N (P), N, and S. On the other hand, composite $\mathrm{E}$ shows a lower level of friction and higher frictional fluctuations. These behaviors of composite $\mathrm{E}$ may be attributed to the reduction of interfacial adhesion at the friction interface because of lower mechanical strength (see Table 3 ) or lower shear strength of the transfer film. Reducing interfacial adhesion and interfacial stress lowers the level of friction and COF for composite $\mathrm{E}$. In addition, easy rupturing of the interfacial bonds during continuous sliding for composite $E$ due to its lower mechanical strength could also be related to the lower COF and higher frictional fluctuations. A similar observation was also reported by Saffer and Shojaei [11].

Wear is a complex phenomenon that depends on variables like applied load, temperature, sliding velocity, sliding time, properties of friction pair, and mechanical strength of tribo-layer formed at friction interface [22]. According to Cho et al. [23], the wear of a friction material depends on the thermal stability and reinforcing effect of the constituting ingredients. Figure 3 shows the volume wear of the composites while Fig. 4 illustrates the influence of different rubbers on the specific wear rate of the composites. Composite $\mathrm{E}$ exhibits a higher specific wear rate than the others. Interestingly, both NBR-based composites i.e. N $(\mathrm{P})$ and $\mathrm{N}$ show comparable specific wear rates. The high specific wear rate of composite $E$ could be because of the larger high-pressure surface area compared to others. This is because the bonding strength between EPDM and PF resin is relatively weak compared to the bonding strength of other composites, as predicted from the lower flexural and compressive strength of composite E. Therefore, 


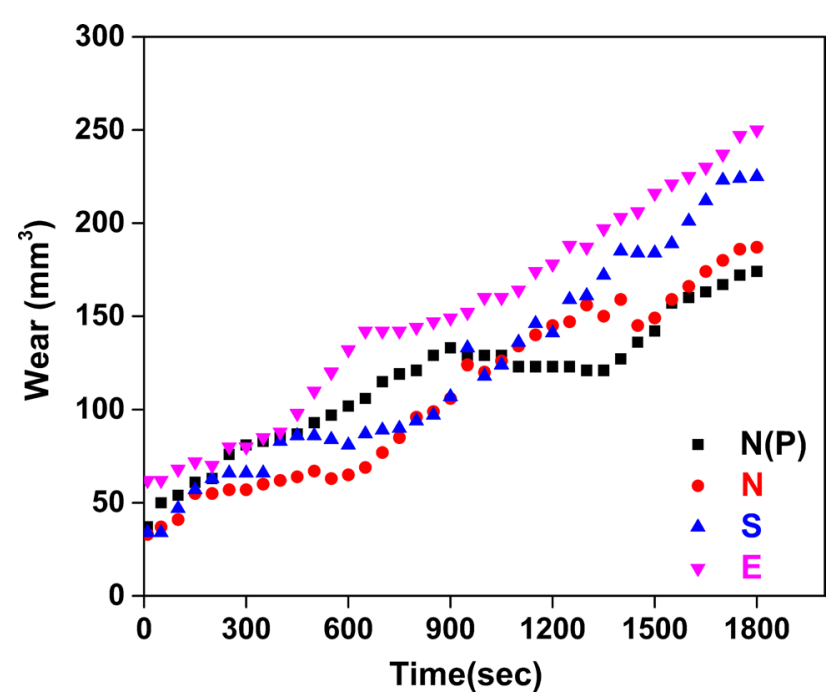

Fig. 3 Wear (volume) as a function of sliding time of different rubber-based composites

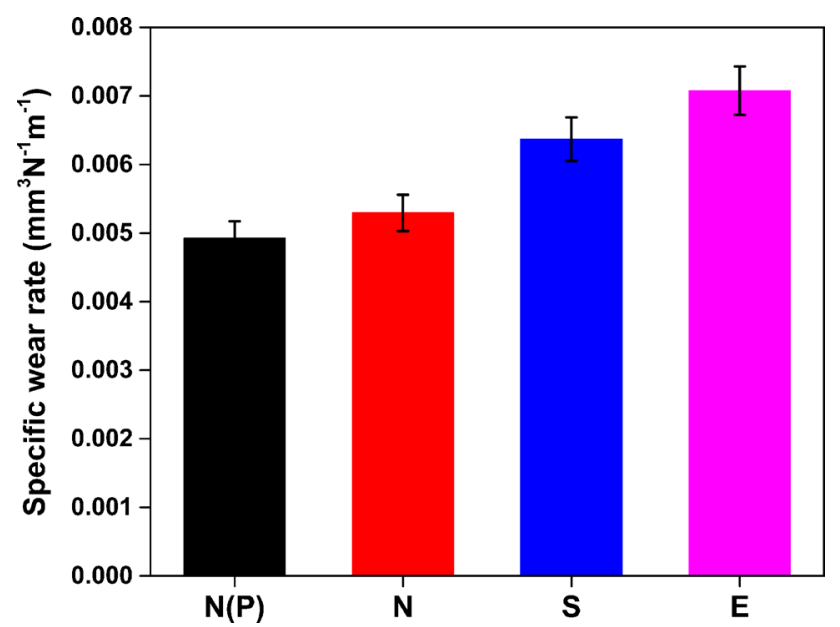

Fig. 4 Specific wear rate of different rubber-based composites

composite E can produce a larger amount of wear debris (see Fig. 9) which results in high specific wear rate [24].

Figure 3 suggests that NBR (both powder and bale) improves wear resistance of the composites, but the other two rubbers (SBR and EPDM) increase the wear loss. Surface energy of non-polar EPDM is the lowest among the three rubbers, so less interfacial interaction with $\mathrm{PF}$ resin is expected which may be attributed to the poor wear resistance of composite E. On the other hand, polar NBR can make better interfacial interactions with PF matrix that may be related to the superior wear resistance of composites N (P) and N. SBR based composite $S$ shows intermediate wear behavior. Wear loss of all composites increases continuously; although not linear with sliding time (see Fig. 3). Saffer et al. [13] reported that the non-linearity in wear loss versus sliding time graph could be associated with the significant change in material properties, particularly the change like rubber-to-glass transition. According to Fig. 3, all composites exhibit rubber-to-glass transition phenomenon, although it is more prominent for the NBR based composites and less significant for the EPDM based composite. Therefore, composite E shows more rubber-like behavior, and its wear loss is higher due to the lower mechanical properties at the rubbery state because wear behavior of the composites is closely related to their mechanical properties, especially the hardness. Kim et al. [25] suggested an approximate linear relationship between hardness and wear rate that higher the hardness, higher is the wear rate. Therefore, hardness can give an indirect measure of wear resistance. As discussed above, the higher wear rate of composites $E$ and $S$ could be related to the lower mechanical properties (see Table 3) due to the improper dispersion of rubber phase in PF matrix. Abrasive wear is more likely the dominant mechanism for composite $E$, as this mechanism is related to the surface hardness [26]. In general, rubber enhances shock absorbing ability and imparts flexibility to the filler-loaded friction composites. Rubber also increases conformability of the friction material with the counter face by raising the contact area. However, rubber possesses lower surface energy than the matrix resin, which can vary from rubber to rubber [27]. Therefore, the interaction of rubber with resin depends on the chemical structure and also on the polarity of the rubber. In addition, the interaction between the rubber phase and matrix PF resin has a strong influence on the formation of primary plateaus, which minimizes wear loss. Figure 9 shows a less number of primary plateaus on the worn surface of $E$, thus a less stable and non-uniform third body layer of wear debris formation is expected at the friction interface of composite $E$ and experiences the highest wear loss.

\subsection{Thermogravimetric analysis}

Figure 6 presents thermogravimetric (TG) and derivative thermogravimetric (DTG) plots of the composites and Fig. 5 shows those of the pure PF resin. TGA of pure PF resin is done to analyze and compare the effect of different rubbers on the thermal stability of the composites. TG curve of pure PF resin reveals its major decomposition happens at $\sim 300^{\circ} \mathrm{C}$. TG curves of the composites show three major degradation stages that characterize the thermal behavior of the composites. Table 4 summarizes the characteristics segments of the thermograms. The first major degradation which accounts for the maximum weight loss of the composites occurs at $\sim 350^{\circ} \mathrm{C}$. The second degradation happens at $\sim 500{ }^{\circ} \mathrm{C}$, and the final degradation starts above $600{ }^{\circ} \mathrm{C}$. The DTG curves of the composites also support 


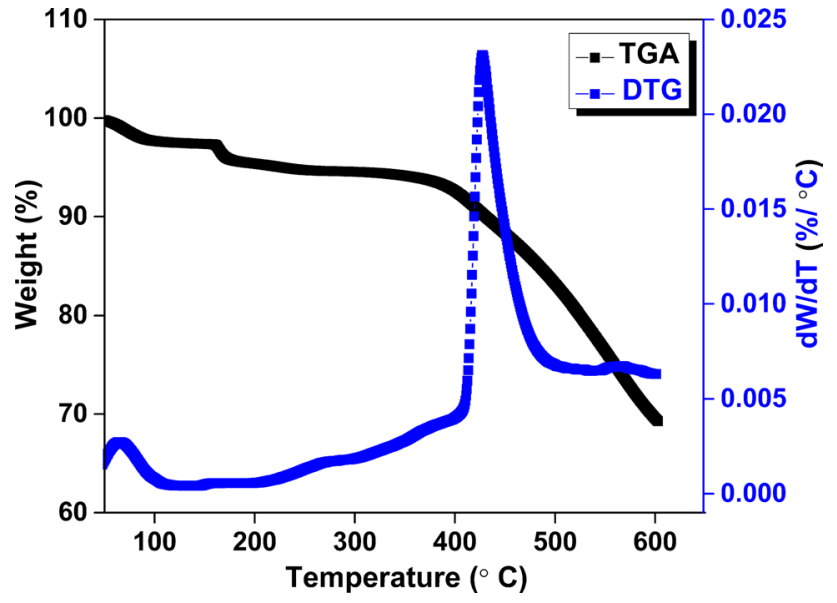

Fig. 5 TG/DTG curves of pure phenolic resin

Table 4 Analysis of thermograms of pure phenolic resin and different composites

\begin{tabular}{llll}
\hline Composite & $\begin{array}{l}\text { Onset tempera- } \\
\text { ture }\left({ }^{\circ} \mathrm{C}\right)\end{array}$ & $\mathrm{T}_{\max }\left({ }^{\circ} \mathrm{C}\right)$ & $\begin{array}{l}\text { Weight resi- } \\
\text { due at } 800{ }^{\circ} \mathrm{C} \\
(\%)\end{array}$ \\
\hline PF resin & 210 & 430 & 56.7 \\
$\mathrm{~N}(\mathrm{P})$ & 250 & 454 & 82.4 \\
$\mathrm{~N}$ & 310 & 454 & 86.1 \\
$\mathrm{~S}$ & 260 & 457 & 84.1 \\
$\mathrm{E}$ & 265 & 475 & 84.9 \\
\hline
\end{tabular}

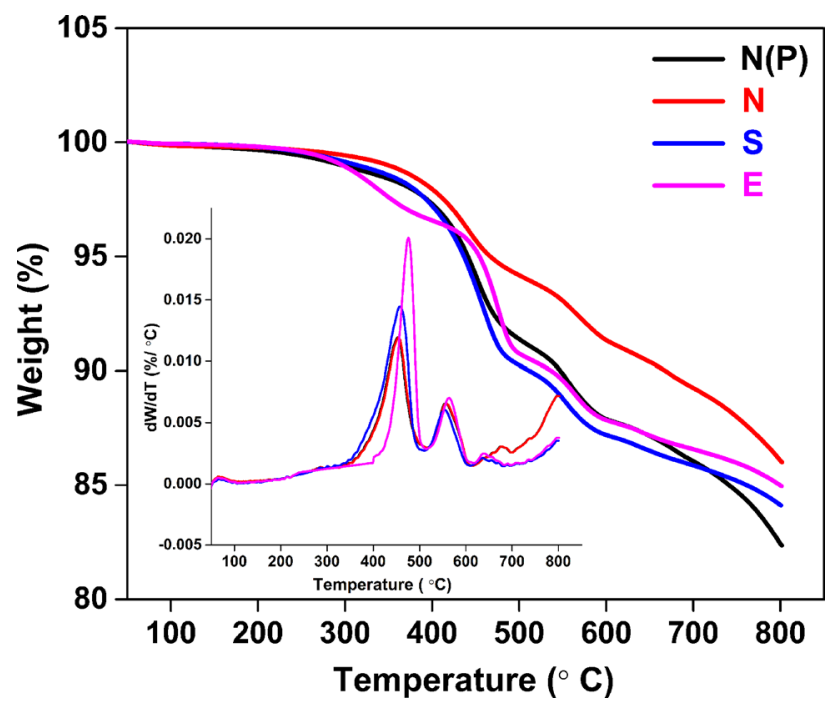

Fig. 6 TG curves (weight vs. temperature) of different rubber-based composites; Inset Figure is the derivative weight vs. temperature plots of the composites

three degradation peaks. The initial degradation is due to the decomposition of PF resin and other organic components, including rubber particles vulnerable to thermal decomposition at a lower temperature (below $300^{\circ} \mathrm{C}$ ) [28]. Literature suggests that $\mathrm{PF}$ resin decomposes at $\sim 300^{\circ} \mathrm{C}$ and degrades severely above $350{ }^{\circ} \mathrm{C}$ producing various volatile products [29]. The relative proportion of PF resin is large in all composites than the rubber component, thus the initial degradation may be correlated to the decomposition of PF resin. However, the rubber component certainly affects the initial rate of decomposition as TG curves of composites $\mathrm{N}$ and $\mathrm{N}(\mathrm{P})$ shift to the higher temperatures relative to composites $S$ and $E$ (see Fig. 6). NBR decreases the initial rate of thermal degradation, but EPDM based formulation (E) shows a higher rate of initial degradation. This may be because NBR has higher thermal stability than EPDM or SBR, thus NBR improves the thermal resistance to degradation.

The second degradation happens in the composites at $\sim 500^{\circ} \mathrm{C}$. This degradation happens because of the degradation of aramid pulp [30], the other organic component present in the system. DTG curve reveals that the second degradation takes place to a lower extent compared to the first degradation (see Fig. 6). This is because the proportion of aramid pulp is less compared to the other organic components, especially PF resin. The third and final step of degradation occurs above $700^{\circ} \mathrm{C}$, which may be due to the minute weight loss of graphite powder, as reported in [31]. Table 4 shows that the increasing content of residual char mass (weight $\%$ ) at $800^{\circ} \mathrm{C}$ is in the increasing order of $\mathrm{N}(\mathrm{P})<\mathrm{S}<\mathrm{E}<\mathrm{N}$. Composite $\mathrm{N}$ exhibits overall good resistance to thermal degradation while composite $\mathrm{S}$ shows poor resistance to thermal degradation. Interestingly, composite $\mathrm{E}$ shows less thermal stability at the lower temperatures but shows better thermal stability at the higher temperatures than $\mathrm{S}$ or $\mathrm{N}$. This may be explained as the composite E yields higher residual char, the char layer provides higher insulation barrier to heat flow into the bulk of the composite thereby raising the thermal stability of composite E above $800^{\circ} \mathrm{C}$ [32].

The variations in COFs and specific wear rate of the composites with sliding time are closely related to the friction-induced heat that accelerates the degradation and decomposition of PF resin and other organic components present in the system. Increasing interface temperature can have a fatal effect on the friction and wear behavior of the composites because the adhesive ability of $\mathrm{PF}$ resin becomes weak at high temperatures which promotes the delamination of filler particles and reinforcing elements from the matrix resin, and decreases the mechanical strength and wear resistance of the composites [33]. Hence, the heat resistance and friction properties of the composites substantially depend on the thermal properties of PF resin. As discussed earlier, the excellent frictional stability and good wear resistance of composite $\mathrm{N}$ (P) could be related to the better dispersion of NBR powder 
in PF matrix, which facilitates the interfacial chemical reactions between the rubber particles and PF resin. Liu et al. [14] also found that PF resin modified with NBR powder (nano-scale) has a much higher impact strength and heat resistance than PF resin modified with conventional rubbers, which they believed to be responsible for the better friction performance at the high temperatures. According to Fig. 6, SBR and EPDM based composites exhibit higher sensitivity to friction-induced heat, which may be the plausible reason for higher wear rates of composites $\mathrm{S}$ and $\mathrm{E}$.

\subsection{Thermal conductivity}

Thermal conductivity is related to the thermo-mechanical behavior of the friction composites. Figure 7 gives thermal conductivity variation of the composites with rubbers. According to Fig. 7, thermal conductivity of the composites changes very little with the rubber component and ranges in between 0.27 and $0.43 \mathrm{~W} / \mathrm{m} \mathrm{K}$. Composite $\mathrm{N}(\mathrm{P})$ exhibits the lowest thermal conductivity, whereas composite $E$ shows the highest value. The increasing order of thermal conductivity of the composites is in the following order: $\mathrm{N}(\mathrm{P})<\mathrm{S}<\mathrm{N}<\mathrm{E}$. In general, rubbers are bad conductors of heat and possess almost identical thermal conductivity. Therefore, the difference in microstructure of the composites due to the difference in dispersion of the rubber phase in PF matrix could be the reason for the minute difference in thermal conductivity of the composites as reported in [34]. The microstructure of the composites can be described with the help of SEM pictures of the composites captured before the friction test (see Fig. 8). According to Fig. 8, there are significant differences in microstructure of the composites. SEM images of $\mathrm{N}(\mathrm{P})$ and $\mathrm{S}$ show the existence of many microvoids on the surface of these two composites. However, the micrograph of E presents less

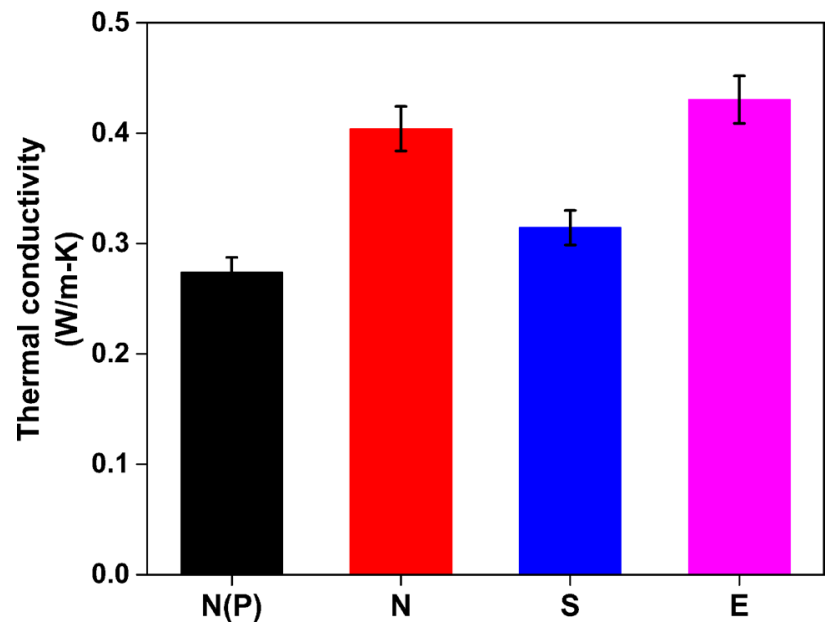

Fig. 7 Thermal conductivity of the composites number of microvoids formations. Benazzouk et al. [35] reported that the microvoids create air voids in a composite and reduce the weight of the specimen and simultaneously lower the thermal conductivity. Hence, the lower thermal conductivity of $\mathrm{N}(\mathrm{P})$ or $\mathrm{S}$ than $\mathrm{E}$ and $\mathrm{N}$ may be attributed to the presence of a large number of microvoids in their microstructure.

Microvoids in a friction composite disturb the interconnectivity of the thermal conductive network, therefore decrease thermal conductivity. In general, thermal conduction in the multi-phase friction composite happens through the transfer of phonon particles across the phase boundary. However, the scattering of phonon particles at the filler-matrix interphase reduces thermal conductivity of the friction composite [36]. Presence of conductive fillers such as metal, graphite in friction composite can reduce scattering of phonon and increase thermal conductivity of the composite by lowering impedance mismatch at the filler-matrix interphase. During the processing of the composites, especially molding and post-curing, microvoids form in the composites which could lead to high impedance mismatch at the phase boundary, thus inhibit phonon transfer and lower thermal conductivity. Hence, the lower thermal conductivities of composites $\mathrm{N}$ $(\mathrm{P})$ and $\mathrm{S}$ may be the result of a large number of microvoids formations in their microstructure during fabrication.

Thermal conductivity has a direct influence on COFs of the composites (see Figs. 2 and 7). According to Mahale and Bijwe [37], a high average COF is associated with a large amount of heat generation at the friction interface which raises the disc temperature. Therefore, the disc temperature rise during braking should be as small as possible because that reduces the counter face friendliness of the friction material. Rising temperature causes a decrease in performance COF (known as thermal fade) due to the degradation of organic components present in the system and leads to the formation of primary and secondary plateaus. High thermal conductivity facilitates the dissipation of frictional heat from the friction interface and helps to retain the structural integrity of the friction composites. In general, NAO friction composites have low thermal conductivity (less than $1 \mathrm{~W} / \mathrm{m} \mathrm{K}$ ). Increasing thermal conductivity can reduce the contact surface temperature, and hence control the thermal fade phenomenon. Composite $N(P)$ has the lowest thermal conductivity, highest average COF, and lowest specific wear rate. On the other hand, composite $\mathrm{E}$ exhibits the highest thermal conductivity, highest frictional fluctuations, and highest specific wear rate. The low thermal conductivity of composite $N(P)$ could help to maintain sufficient heat at the friction interface, so PF resin can bind the worn-out fibers and fillers, and form a stable tribo-layer at the friction interface. Therefore, the stable tribo-layer formation could be attributed to the 

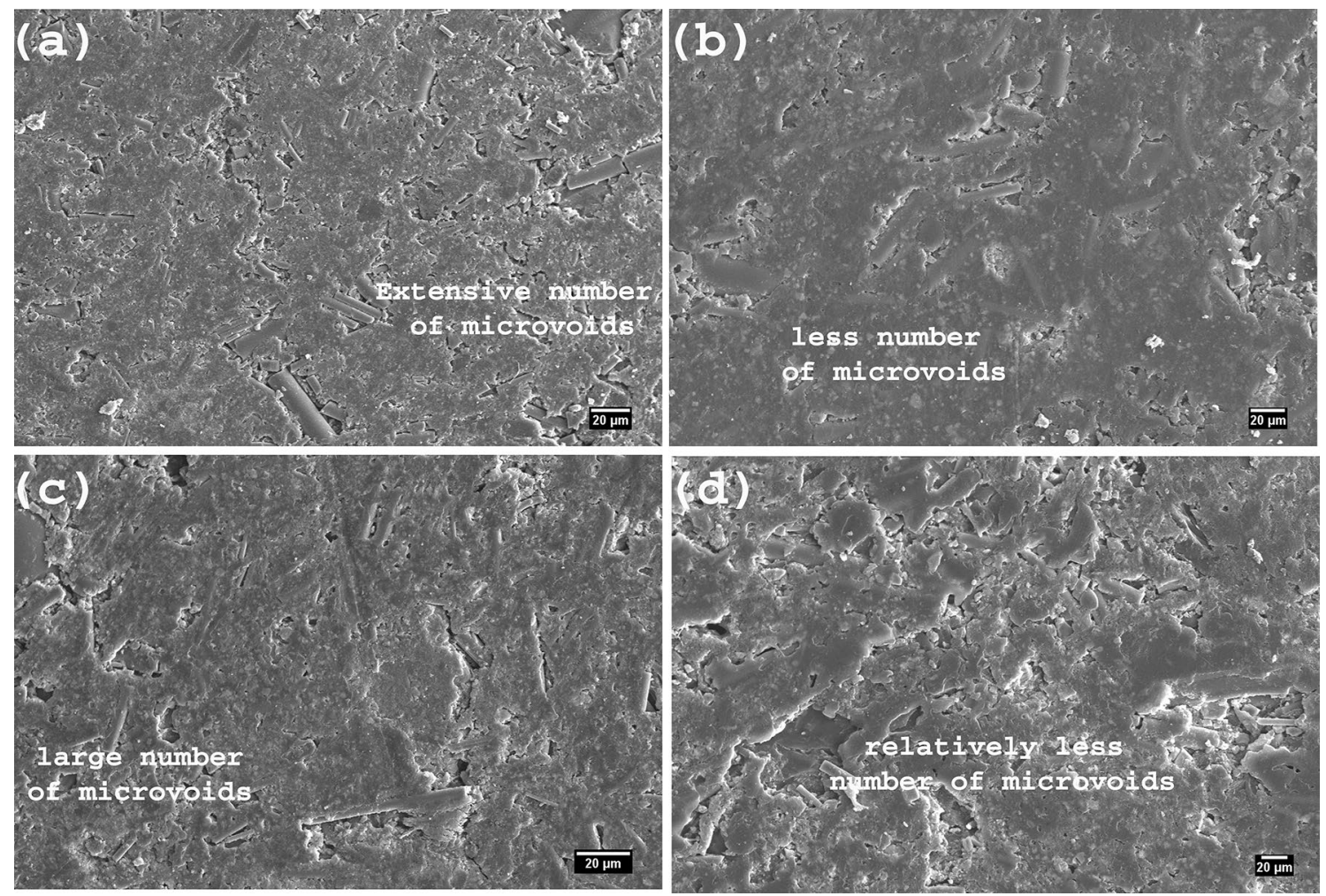

Fig. 8 SEM micrographs of the surfaces of the composites before friction test: (a) composite N (P), (b) composite N, (c) composite S, (d) composite $\mathrm{E}$

lowest specific wear rate of composite $N(P)$. But, in the case of composite $\mathrm{E}$, the temperature rise at the interface may not be sufficient for the PF resin present in the tribolayer to bind the surrounding fibers and fillers, hence there is a chance of disintegration of the tribo-films which raises frictional fluctuation and wear loss of composite E. Therefore, the influence of thermal conductivity should also be considered a prime factor that affects the tribological properties of the composites.

\subsection{Worn surface morphological analysis}

Understanding worn surface morphology such as wear debris, primary and secondary plateaus, and micro-cracks could better explain tribological properties of the friction composites [38]. SEM analyses are done to characterize the worn surface morphologies of the composites for understanding friction and wear behaviors, and corresponding wear mechanisms. Figure 9a-d shows the SEM micrographs of the worn surfaces of the composites. According to Fig. 9a-d, SEM image of the worn surface of composite $N(P)$ (Fig. 9a) differs greatly from the others even from $N$ (see Fig. 9b). This different surface morphology of $N$ (P) could be because of polar NBR powder as discussed earlier. Secondary contact plateaus are seen on the worn surface of $\mathrm{N}(\mathrm{P})$ which may also improve the wear resistance. In composite $N(P)$, the secondary plateaus have strongly adhered to the composite surface, thus covering the matrix surface and protect the underlying layers, and the material loss from the matrix surface through abrasive wear reduces significantly [39]. The worn surface morphology of composite $\mathrm{N}$ (Fig. 9b) exhibits a large number of secondary plateaus, voids, and grooves. According to Poletto et al. [40], secondary plateau formation is influenced by operating variables like contact pressure, sliding speed, sliding time, and temperature. These secondary plateaus can take part in the formation of a third body friction layer which plays an important role in the brake friction performance of the composites as reported in [41]. Secondary contact plateaus play a dominant role in improving the friction and wear performance of composite N. Therefore, the stable COF (see Fig. 1) and low specific wear rate (see Fig. 4) of composite $\mathrm{N}$ could be attributed to a large number of secondary contact patches on the worn surface of composite N. In addition, the voids present on the worn surface of $\mathrm{N}$ may accommodate hard particles and other worn-out particles, and reduce the abrasive wear loss as observed in Fig. 3.

The differences in COFs, specific wear rate, and wear mechanism of composite $N(P)$ and $N$ are likely because of 

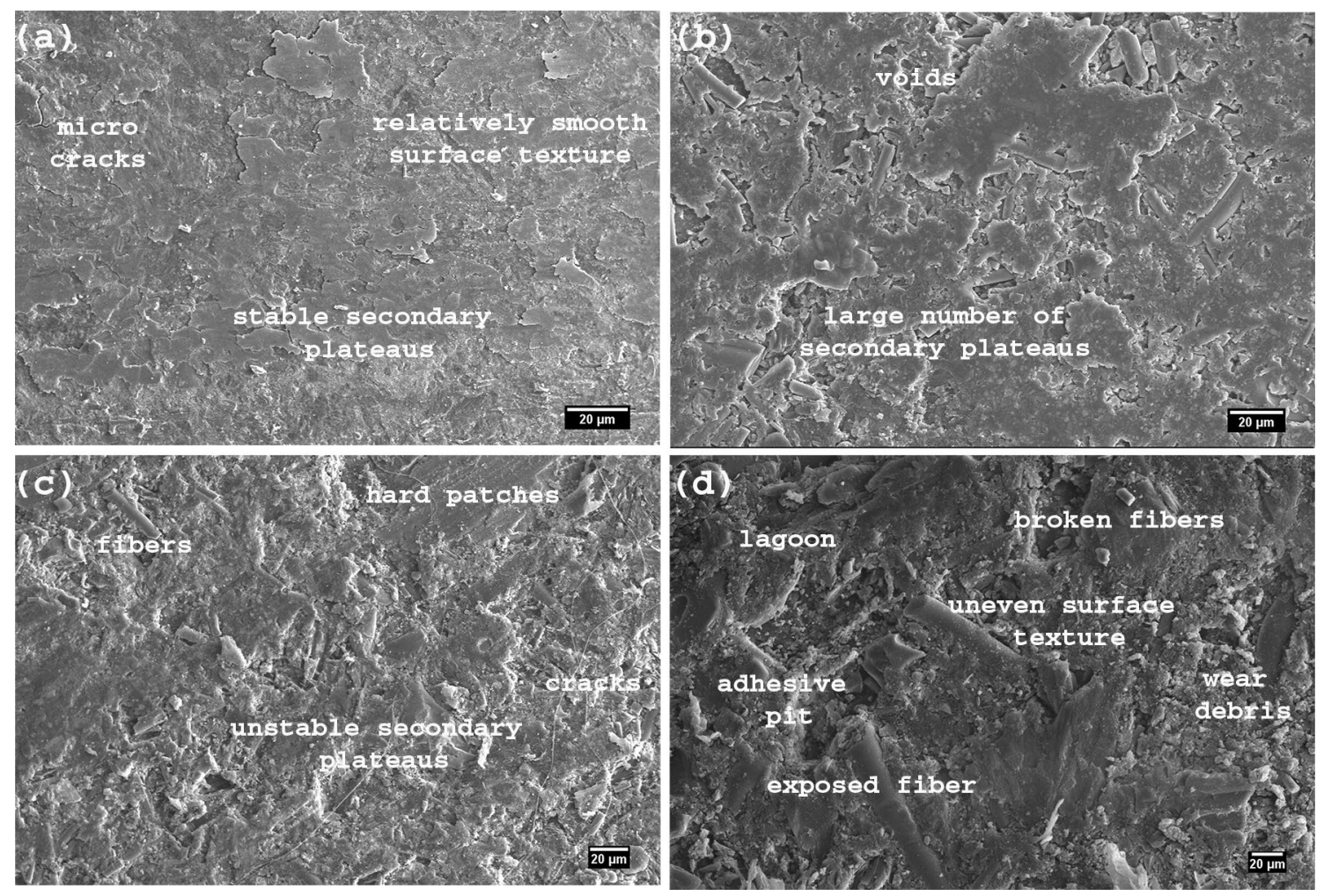

Fig. 9 SEM micrographs of the worn surfaces of the composites after friction test: (a) composite N (P), (b) composite N, (c) composite S, (d) composite $\mathrm{E}$

the effect of dispersion of rubber phase on plateau formation on the worn surface of the respective composite. The secondary contact plateaus compact better with smaller wear debris because of the high specific surface area. The wear debris in composite $\mathrm{N}$ results from large size rubber particles and consists mainly of the loose matrix, whereas the wear debris in $\mathrm{N}(\mathrm{P})$ forms from small rubber particles and consists of all ingredients including the fibrous reinforcements. The large size wear debris in $\mathrm{N}$ is involved in small contact plateaus formation due to the elastic nature of large rubber particles. Small size wear debris in composite $\mathrm{N}(\mathrm{P})$ promotes stable secondary plateau formation and reduces the number of high-pressure zone on the sliding surface. This suggests that the dispersion of polar NBR in PF matrix resin strongly affects the tribological performance of the friction composites, and acts as a control parameter to achieve the optimum properties required for advanced brake performance. A similar observation was reported by Chang et al. [15].

Figure $9 \mathrm{c}$ shows that the worn surface of composite $\mathrm{S}$ is relatively smooth compared to that of composite $E$ with some cracks and hard patches. According to Ma et al. [42], uneven mixing of raw ingredients in a composite matrix could generate cracks because of differential thermal expansion of different zones on the sliding surface. The formation of cracks on the worn surface of composite $S$ can be ascribed to the reduction of compactness of secondary contact plateaus because of lower thermal stability (see Fig. 6) [43]. The cracks also indicate that the secondary plateaus are not stable. This reasoning supports the high specific wear rate (although lower than composite E) of composite S. Cracks indicate typical fatigue wear while hard patches are generated through abrasive wear. Hence, composite $S$ experiences both abrasive wear and fatigue wear during friction test. EPDM rubber-based composite E exhibits the least wear resistance while both the NBRbased composites show better wear resistance (see Figs. 3 and 4). According to Fig. 9d, the worn surface of composite $E$ is thoroughly uneven and displays a very rough topography. Figure $9 \mathrm{~d}$ also shows pulling-out of fibers and wearing of particles from the matrix surface during friction test. Composite $\mathrm{E}$ does not show a significant back transfer of wear debris to its surface. The back transferred worn-out particles may act as a protective layer to the underlying surfaces and reduce wear loss through adhesive interaction with the friction composite as reported in [44]. Unfortunately, the said protection is not there for composite $E$ and exhibits the highest wear loss (see Fig. 3).

Noticeably, Fig. $9 \mathrm{~d}$ shows adhesive pit, lagoon, broken fibers, and wear debris on the worn surface of composite 
E. The broken fibers corroborate that the interfacial bonding between the fibers and matrix is weak in composite $\mathrm{E}$; likely because of non-polar EPDM rubber, and PF matrix can't bind the fibers under the shearing force during sliding. The delaminated broken fibers and other hard particles can act as a third body abrasive layer and aggravate the damage of the composite surface, and subsequently increase the wear loss as seen in Fig. 3. In general, wear debris forms because of uneven distribution of fibers and fillers in the composite matrix which creates loose matrix and broken fibers during the physical movement between the counter disc and friction material under the combined action of mechanical shearing and heat. Fibers and other hard particles promote the formation of primary contact plateaus, whereas the surrounding lowlands formed by accumulation and compaction of wear debris results in secondary contact plateaus formation. According to $\mathrm{Ji}$ et al. [45], the ingredients of friction material, especially the reinforcing ingredients, strongly affect the formation of contact plateaus. The primary plateaus take away the load from the secondary plateaus [46]. However, primary and secondary plateaus together increase the real contact areas and decrease the contact pressure. Hence, the plateau area fraction significantly changes the sliding contact conditions and level of friction at the interface as reported by Wahlström [47]. Formation of wear debris on the worn surface of composite E suggests that an abrasive wear mechanism is operative during friction test. Again, adhesive pit and lagoon formations due to shearing action at the friction interface support the adhesive wear. Therefore, both abrasive and adhesive wear is operating for composite $E$ for which it exhibits the highest specific wear rate (see Fig. 4).

\section{Conclusions}

In summary, phenolic resin embedded elastomeric phases were strategically developed by varying the polar and non-polar elastomer components using the physical mixing method to enhance the tribological performance of the brake friction composites. The choice of such a rubberresin blend was accounted for in the present study where the rubber phase and its polarity played a key role in delayed stress dissipation, while the hard resin phase provided the intrinsic strength to the composites. In the case of NBR (powder)-phenolic composite, the highest average COF of 0.52 was obtained, whereas EPDM based composite showed the least average COF $(0.36)$ and the highest frictional fluctuations. NBR (powder)-based composite also exhibited $\sim 1.5$ times better specific wear rate than EPDMbased composite. This could be due to a better polar-polar interaction between the phenolic system and NBR phase.
Such interfacial anchoring between the rubber and phenolic phase becomes dormant in the case of non-polar elastomeric phase. Moreover, polar NBR also synergistically improved the thermal stability, which is an additional longevity criterion of the composite. However, thermal conductivity for EPDM $(0.43 \mathrm{~W} / \mathrm{m} \mathrm{K})$ was calculated as the best value with respect to NBR-phenolic composites. Morphological analyses of the worn surfaces of the composites revealed that the dispersion of rubber phase in phenolic matrix played the dominant role in transforming the wear mechanism from abrasive to adhesive. The results of this work could provide a valuable guideline to select proper elastomer component to develop a high-performance phenolic resin-based organic brake friction material for optimum tribo-mechanical performances.

Acknowledgements The authors sincerely acknowledge the financial support of the funding agency "Research Design and Standards Organization" (RDSO), Lucknow, India to carry out the research work.

\section{Compliance with ethical standards}

Conflict of interest The authors declare that they have no conflict of interest to disclose.

\section{References}

1. Xiao Y, Zhang Z, Yao P, Fan K, Zhou H, Gong T, Zhao L, Deng M (2018) Mechanical and tribological behaviors of copper metal matrix composites for brake pads used in high-speed trains. Tribol Int 119:585-592

2. Ji Z, Luo W, Zhou K, Hou S, Zhang Q, Li J, Jin H (2018) Effects of the shapes and dimensions of mullite whisker on the friction and wear behaviors of resin-based friction materials. Wear 406:118-125

3. Pai A, Kini MV, Pokharel V (2017) Influence of a novel hardener p-toluene sulfonic acid on mechanical and wear response of phenolic-based friction materials. Tribol Trans 60(5):770-780

4. Singh T, Patnaik A, Chauhan R, Chauhan P (2018) Selection of brake friction materials using hybrid analytical hierarchy process and vise Kriterijumska Optimizacija Kompromisno Resenje approach. Polym Compos 39(5):1655-1662

5. Cai P, Wang T, Wang Q (2016) Formulation optimization of friction material with golden section approach. Tribol Trans 59(1):28-32

6. Mahale V, Bijwe J, Sinha S (2017) Influence of nano-potassium titanate particles on the performance of NAO brake-pads. Wear 376:727-737

7. Ertan R, Yavuz N (2010) An experimental study on the effects of manufacturing parameters on the tribological properties of brake lining materials. Wear 268(11-12):1524-1532

8. Cai P, Wang T, Wang Q (2015) Effect of several solid lubricants on the mechanical and tribological properties of phenolic resinbased composites. Polym Compos 36(12):2203-2211

9. Derakhshandeh B, Shojaei A, Faghihi M (2008) Effects of rubber curing ingredients and phenolic-resin on mechanical, thermal, and morphological characteristics of rubber/phenolic-resin blends. J Appl Polym Sci 108(6):3808-3821 
10. Arjmand M, Shojaei A (2010) Tribological characteristics of rubber-based friction materials: effects of steel wool and aramid pulp. Tribol Lett 41(2):325-336

11. Saffar A, Shojaei A (2012) Effect of rubber component on the performance of brake friction materials. Wear 274:286-297

12. Bijwe J (2007) NBR-modified resin in fade and recovery module in non-asbestos organic (NAO) friction materials. Tribol Lett 27(2):189-196

13. Saffar A, Shojaei A, Arjmand M (2010) Theoretical and experimental analysis of the thermal, fade and wear characteristics of rubber-based composite friction materials. Wear 269(1-2):145-151

14. Liu Y, Fan Z, Ma H, Tan Y, Qiao J (2006) Application of nano powdered rubber in friction materials. Wear 261(2):225-229

15. Chang $\mathrm{YH}$, Joo BS, Lee $\mathrm{SM}$, Jang $\mathrm{H}$ (2018) Size effect of tire rubber particles on tribological properties of brake friction materials. Wear 394:80-86

16. Ghosh P, Banerjee SS, Khastgir D (2020) Elastomer modified phenolic resin-based composites with reduced scale friction: influence of calcined petroleum coke on tribological and thermomechanical behavior. Polym Eng Sci 60(7):1446-1458

17. Gweon JH, Joo BS, Jang H (2016) The effect of short glass fiber dispersion on the friction and vibration of brake friction materials. Wear 362:61-67

18. Park JS, Lee SM, Joo BS, Jang H (2017) The effect of material properties on the stick-slip behavior of polymers: a case study with PMMA, PC, PTFE, and PVC. Wear 378:11-16

19. Lee $S$, Shin $M$, Jang $H$ (2013) Friction-induced intermittent motion affected by surface roughness of brake friction materials. Wear 308(1-2):29-34

20. Eriksson M, Jacobson S (2000) Tribological surfaces of organic brake pads. Tribol Int 33(12):817-827

21. Smith RH (2008) Analyzing friction in the design of rubber products and their paired surfaces. CRC press, Boca Raton, FL

22. Kim SJ, Jang H (2000) Friction and wear of friction materials containing two different phenolic resins reinforced with aramid pulp. Tribol Int 33(7):477-484

23. Cho MH, Kim SJ, Kim D, Jang $\mathrm{H}$ (2005) Effects of ingredients on tribological characteristics of a brake lining: an experimental case study. Wear 258(11-12):1682-1687

24. Wenbin L, Jianfeng H, Jie F, Zhenhai L, Liyun C, Chunyan Y (2016) Effect of glass powder content on the mechanical and wet tribological properties of carbon fabric/phenolic composites. J Mater Sci 51(9):4419-4430

25. Kim YC, Cho MH, Kim SJ, Jang H (2008) The effect of phenolic resin, potassium titanate, and CNSL on the tribological properties of brake friction materials. Wear 264(3-4):204-210

26. Arjmand M, Shojaei A (2011) Tribological characteristics of rubber-based friction materials. Tribol Lett 41(2):325-336

27. Shojaei A, Faghihi M (2010) Physico-mechanical properties and thermal stability of thermoset nanocomposites based on styrene-butadiene rubber/phenolic resin blend. Mater Sci Eng A 527(4-5):917-926

28. Lee J-J, Lee J-A, Kwon S, Kim J-J (2018) Effect of different reinforcement materials on the formation of secondary plateaus and friction properties in friction materials for automobiles. Tribol Int 120:70-79

29. Verma PC, Ciudin R, Bonfanti A, Aswath P, Straffelini G, Gialanella $S$ (2016) Role of the friction layer in the high-temperature pinon-disc study of a brake material. Wear 346:56-65

30. Ghosh P, Banerjee SS, Khastgir D (2020) Performance assessment of hybrid fibrous fillers on the tribological and thermomechanical behaviors of elastomer modified phenolic resin friction composite. SN Appl Sci 2(5):788
31. Yasmin A, Daniel IM (2004) Mechanical and thermal properties of graphite platelet/epoxy composites. Polymer 45(24):8211-8219

32. Zhang Y, Zhang Q, Liu Q, Cheng H, Frost RL (2014) Thermal stability of styrene butadiene rubber (SBR) composites filled with kaolinite/silica hybrid filler. JTherm Anal Calorim 115(2):1013-1020

33. Blau PJ (2003) Microstructure and detachment mechanism of friction layers on the surface of brake shoes. J Mater Eng Perform 12(1):56-60

34. Shojaei A, Fahimian M, Derakhshandeh B (2007) Thermally conductive rubber-based composite friction materials for railroad brakes-thermal conduction characteristics. Compos Sci Technol 67(13):2665-2674

35. Benazzouk A, Douzane O, Mezreb K, Laidoudi B, Quéneudec M (2008) Thermal conductivity of cement composites containing rubber waste particles: experimental study and modelling. Constr Build Mater 22(4):573-579

36. Ghahramani N, Seyed Esfahani SA, Mehranpour M, Nazockdast $H$ (2018) The effect of filler localization on morphology and thermal conductivity of the polyamide/cyclic olefin copolymer blends filled with boron nitride. J Mater Sci 53:16146-16159

37. Mahale V, Bijwe J (2020) Exploration of plasma treated stainless steel swarf to reduce the wear of copper-free brake-pads. Tribol Int 144:106111

38. Patnaik A, Kumar M, Satapathy BK, Tomar BS (2010) Performance sensitivity of hybrid phenolic composites in friction braking: effect of ceramic and aramid fibre combination. Wear 269(11-12):891-899

39. Bijwe J, Majumdar N, Satapathy B (2005) Influence of modified phenolic resins on the fade and recovery behavior of friction materials. Wear 259(7-12):1068-1078

40. Poletto J, Barros L, Neis P, Ferreira N (2018) Analysis of the error in the estimation of the morphology of contact plateaus existing on the surface of brake pads. Tribol Int 126:297-306

41. Prabhu TR, Varma V, Vedantam S (2014) Tribological and mechanical behavior of multilayer $\mathrm{Cu} / \mathrm{SiC}+\mathrm{Gr}$ hybrid composites for brake friction material applications. Wear 317(1-2):201-212

42. Ma Y, Liu Y, Wang L, Tong J, Zhuang J, Jia H (2018) Performance assessment of hybrid fibers reinforced friction composites under dry sliding conditions. Tribol Int 119:262-269

43. Leonardi M, Menapace $C$, Matějka V, Gialanella S, Straffelini G (2018) Pin-on-disc investigation on copper-free friction materials dry sliding against cast iron. Tribol Int 119:73-81

44. Ahmadijokani F, Alaei Y, Shojaei A, Arjmand M, Yan N (2019) Frictional behavior of resin-based brake composites: effect of carbon fibre reinforcement. Wear 420:108-115

45. Ji Z, Jin H, Luo W, Cheng F, Chen Y, Ren Y, Wu Y, Hou S (2017) The effect of crystallinity of potassium titanate whisker on the tribological behavior of NAO friction materials. Tribol Int 107:213-220

46. Federici M, Gialanella S, Leonardi M, Perricone G, Straffelini G (2018) A preliminary investigation on the use of the pin-on-disc test to simulate off-brake friction and wear characteristics of friction materials. Wear 410:202-209

47. Wahlström J (2016) A factorial design to numerically study the effects of brake pad properties on friction and wear emissions. Adv Tribol 2016(2):1-10

Publisher's Note Springer Nature remains neutral with regard to jurisdictional claims in published maps and institutional affiliations. 